\title{
Impact of Saharan Dust on Severe Small for Gestational Births in the Caribbean
}

\author{
Jean-François Viel, ${ }^{1 \star}$ Léah Michineau, ${ }^{2}$ Céline Garbin, ${ }^{3}$ Christine Monfort, ${ }^{4}$ Philippe Kadhel, ${ }^{5}$ \\ Luc Multigner, ${ }^{4}$ and Florence Rouget ${ }^{1}$ \\ ${ }^{1}$ Univ Rennes, CHU Rennes, Inserm, EHESP, Irset (Institut de Recherche en Santé, Environnement et Travail) - UMR S 1085 , \\ Rennes, France; ' ${ }^{2}$ Univ Rennes, Inserm, EHESP, Irset (Institut de Recherche en Santé, Environnement et Travail) - UMR_S 1085, \\ Pointe-à-Pitre, France; ${ }^{3}$ Gwad'Air, Air Quality Monitoring Agency, Petit-Bourg, France; ${ }^{4}$ Univ Rennes, Inserm, EHESP, Irset \\ (Institut de Recherche en Santé, Environnement et Travail) - UMR_S 1085, Rennes, France; ${ }^{5}$ Univ Antilles, CHU Guadeloupe, \\ Univ Rennes, Inserm, EHESP, Irset (Institut de Recherche en Santé, Environnement et Travail) - UMR_S 1085, Pointe-à-Pitre, France
}

Abstract. Desert dust transported from the Sahara to the Caribbean generates peak exposures to particulate matter $\leq 10 \mu \mathrm{m}$ $\left(\mathrm{PM}_{10}\right)$. We investigated the impact of dust episodes on severe small for gestational-age births in Guadeloupe. The study sample consisted of 911 pregnant women enrolled in the Timoun mother-child cohort. Desert dust exposure was assessed through the mean daily $\mathrm{PM}_{10}$ concentrations averaged over the entire pregnancy. Numerous sociodemographic and medical risk factors were considered as covariates and introduced into multinomial logistic regression models. Odds ratios (ORs) were calculated per SD change $\left(3.08 \mu \mathrm{g} / \mathrm{m}^{3}\right)$. Among various outcomes, symmetrically growth-retarded births showed the highest OR (3.28, $95 \% \mathrm{Cl}: 1.08-10.02)$. Saharan dust seems to influence weight but not length or head circumference at birth. Given the high OR observed in this study, it is conceivable that Saharan dust plays a role through severe placental insufficiency early in pregnancy.

\section{INTRODUCTION}

Saharan dust transported to Europe, the Caribbean, and the Americas increases particulate matter (PM) levels in the countries in these downwind regions. In Europe, although some studies have linked sandy dust storms to a range of adverse health outcomes including respiratory and cardiovascular conditions and mortality, others have found no harmful effect. ${ }^{1}$ The same inconsistencies emerge from studies published in the Caribbean region. ${ }^{2-5}$

Although an increasing number of studies have shown that maternal exposure to air PM can affect the developing fetus (resulting in, among other outcomes, small for gestational-age [SGA] births), ${ }^{6}$ available evidence on the effects of dust outbreaks on pregnancy is very scarce. ${ }^{7,8}$ We aimed to investigate the impact of Saharan dust episodes on severe SGA births among a population of pregnant women in the French Guadeloupe archipelago (an outermost region of the European Union situated in the Caribbean basin) using prospectively collected individual data.

\section{METHODS}

The study population and exposure assessment have been fully described elsewhere. ${ }^{8}$ In brief, 1,068 women were enrolled successively in the Timoun cohort during their third trimester prenatal visit, between 2004 and 2007 . The participants were representative of pregnant women giving birth in the local public hospitals, which accounts for $70 \%$ of all deliveries in Guadeloupe. In this report, we excluded women not born in the Caribbean, cases involving multiple births, severe birth defects, and induced pregnancies after fertility treatment, resulting in a study sample of 911 women. Gestational age was based on the first day of the last menstrual period and was confirmed or corrected by ultrasound. French fifth centiles, stratified for gestational age at delivery and infant gender, ${ }^{9}$ were used to

\footnotetext{
*Address correspondence to Jean-François Viel, Department of Epidemiology and Public Health, University Hospital, 2 Rue Henri Le Guilloux, Rennes 35033, France. E-mail: jean-francois.viel@univrennes1.fr
}

classify births as severe SGA for weight $\left(S G A_{W}\right)$, length $\left(S G A_{L}\right)$, or head circumference $\left(S G A_{H C}\right)$. The $S G A_{W}$ was further dichotomized into symmetric (proportional) SGA (weight, length, and $\mathrm{HC}$, all below the fifth centile) versus asymmetric (disproportional) SGA.

Desert dust exposure was assessed through the mean daily $\mathrm{PM} \leq 10 \mu \mathrm{m}\left(\mathrm{PM}_{10}\right)$ concentrations (as recorded by the urban background monitoring station situated in Pointe-à-Pitre, economic capital city, center of Guadeloupe) averaged over the entire pregnancy. Numerous risk factors (all referring to the index pregnancy) were considered as covariates and introduced into the statistical models: place of inclusion (i.e., the healthcare facility where pregnant women were enrolled), maternal age, marital status, years of education, body mass index, parity, prior preterm birth, prior miscarriage, prior induced abortions, lupus, history of asthma, chronic hypertension, gestational weight gain, gestational hypertension, gestational diabetes, and urinary tract infection.

Multinomial logistic regression models were used to produce odds ratios (ORs) and their $95 \%$ Cls, calculated per SD change $\left(3.08 \mu \mathrm{g} / \mathrm{m}^{3}\right)$, while adjusting for numerous individual risk factors (see Table 1 footnotes). Statistical analyses were performed using the nnet package from $R$ software (R Foundation for Statistical Computing, Vienna, Austria, 2019).

This study was approved by the Guadeloupean Ethics Committee for studies involving human subjects. Written informed consent was provided by each participant.

\section{RESULTS}

Most pregnant women were enrolled in the study at the University Hospital of Guadeloupe (66.6\%), were aged between 20 and 34 years (58.9\%), were living with a partner (51.4\%), and had completed between 5 and 12 years of education (73.0\%).

Mean $\mathrm{PM}_{10}$ concentrations during pregnancy ranged from 13.17 to $34.92 \mu \mathrm{g} / \mathrm{m}^{3}$. There was an increased adjusted OR for $\mathrm{SGA}_{W}(\mathrm{OR}=1.85,95 \% \mathrm{Cl}: 1.22-2.82, P=0.004)$, whereas the OR was not significantly different from unity for $S G A_{L}$ and $\mathrm{SGA}_{\mathrm{HC}}(\mathrm{OR}=1.03,95 \% \mathrm{Cl}: 0.75-1.41, P=0.84$; OR $=0.93$, $95 \%$ Cl: $0.70-1.25, P=0.65$; respectively) (Table 1). When considering SGA ${ }_{W}$ subtypes, eighteen percent (10/55) of 
TABLE 1

Adjusted ORs* for the risk of severe SGA birth according to the mean $\mathrm{PM}_{10}$ concentration during pregnancy (Timoun cohort, Guadeloupe archipelago, 2004-2007)

\begin{tabular}{|c|c|c|c|c|c|c|}
\hline \multirow[b]{2}{*}{ Category } & \multicolumn{2}{|c|}{ SGA for weight } & \multicolumn{2}{|c|}{ SGA for length } & \multicolumn{2}{|c|}{ SGA for head circumference } \\
\hline & $n$ & $\mathrm{OR} \dagger(95 \% \mathrm{Cl})$ & $n \ddagger$ & $\mathrm{OR} \dagger(95 \% \mathrm{Cl})$ & $n \ddagger$ & $\mathrm{OR} \dagger(95 \% \mathrm{Cl})$ \\
\hline Absence & 854 & 1 & 833 & 1 & 824 & 1 \\
\hline Presence & 57 & $1.85(1.22-2.82)$ & 69 & $1.03(0.75-1.41)$ & 78 & $0.93(0.70-1.25)$ \\
\hline
\end{tabular}

$\mathrm{OR}=$ odds ratio; $\mathrm{PM}_{10}=$ particulate matter $<10 \mu \mathrm{m} ; \mathrm{SGA}=$ small for gestational age.

* Covariates: tobacco smoking, alcohol consumption, maternal age, marital status, years of education, body mass index, parity, prior preterm birth, prior miscarriage, prior induced abortions, asthma, chronic hypertension, gestational weight gain, gestational hypertension, gestational diabetes.

$\dagger$ The ORs were calculated per SD change $\left(3.08 \mu \mathrm{g} / \mathrm{m}^{3}\right)$.

$\ddagger$ Nine missing values.

$S_{\mathrm{SGA}}$ births were symmetrically growth retarded and showed the highest $\mathrm{OR}(\mathrm{OR}=3.28,95 \% \mathrm{Cl}: 1.08-10.02, P=0.04)$. The OR was also elevated for asymmetric SGA but not significantly (OR $=1.52,95 \% \mathrm{Cl}: 0.97-2.40, P=0.07)$ (Table 2).

\section{DISCUSSION}

Saharan dust seems to influence weight but not length or head circumference at birth, while adjusting for sociodemographic and medical risk factors.

This study took advantage of the archipelago-wide Timoun cohort, which collected information on maternal socioeconomic, behavioral, and medical risk factors at an early stage of pregnancy and, therefore, before SGA births occurred. One limitation lies in the Saharan dust exposure, assessed through one single background air quality-monitoring station regardless of the subject's residential location. These monitor-based estimates may have introduced some non-differential measurement error, although the short median bird fly distance $(13.03 \mathrm{~km})$ between the place of residence and the monitoring station siting is reassuring.

The mean $\mathrm{PM}_{10}$ concentrations recorded at the urban background monitoring station rank highly relative to those observed in the largest French mainland cities, despite the absence of heavy industry. Unfortunately, desert dust and locally emitted $\mathrm{PM}_{10}$ (as traffic-related pollution hot spots) contributions are indistinguishably mixed, making this observation difficult to interpret.

Symmetric SGA usually starts in the first trimester of pregnancy, with an overall growth restriction. Given the high OR observed in this study, it is conceivable that Saharan dust plays a role through severe placental insufficiency early in pregnancy. The other two main causes of SGA birth (chromosomal abnormalities and constitutional smallness) seem unlikely, as birth defects were excluded and constitutional

\section{TABLE 2}

Adjusted ORs ${ }^{*}$ for the risk of severe SGA in weight (classified in three categories), according to the mean $\mathrm{PM}_{10}$ concentration during pregnancy (Timoun cohort, Guadeloupe archipelago, 2004-2007)

\begin{tabular}{lcc}
\hline & \multicolumn{2}{c}{ SGA } \\
\cline { 2 - 3 } \multicolumn{1}{c}{ Category } & $n \dagger$ & OR $(95 \% \mathrm{Cl})$ \\
\hline Absence & 843 & 1 \\
Asymmetric & 45 & $1.52(0.97-2.40)$ \\
Symmetric & 10 & $3.28(1.08-10.02)$ \\
\hline OR = odds ratio; PM $_{10}=$ particulate matter $<10 \mu \mathrm{m} ;$ SGA = small for gestational age. \\
${ }^{*}$ Covariates: tobacco smoking, alcohol consumption, maternal age, marital status, years of \\
education, body mass index, parity, prior preterm birth, prior miscarriage, prior induced \\
abortions, asthma, chronic hypertension, gestational weight gain, gestational hypertension, \\
and gestational diabetes. \\
$\quad$ Thirteen missing values. \\
$\quad$ T The ORs were calculated per SD change $\left(3.08 \mu \mathrm{g} / \mathrm{m}^{3}\right)$.
\end{tabular}

smallness is, by definition, independent of any recent environmental exposure. Conversely, asymmetric SGA birth usually occurs during the third trimester, with brain growth relatively spared. We cannot draw firm conclusions concerning this last issue, as etiologies include a large number of maternal, fetal, and placental factors. Many were included in multivariate models, but we cannot exclude residual confounding.

Ambient air pollution can induce systemic inflammation, oxidative stress, and hemodynamic changes, leading to impaired oxygen and nutrient transport to the fetus and subsequent abnormal fetal growth. ${ }^{10}$ Identifying the biological pathways for the effects of desert PM would give more weight to the epidemiological associations found in this study.

Considering the personal and social burden of this adverse pregnancy outcome, the existing warning system with media broadcasting during alert periods could be supplemented. Personalized mobile phone information could be delivered by local authorities to pregnant women about a desert dust cloud moving to the coastline and the relevance of minimizing outdoor activities during the next days.

Received September 20, 2019. Accepted for publication February 4, 2020.

Published online April 13, 2020.

Acknowledgments: We thank the gynecologists, obstetricians, ultrasonographers, midwives, pediatricians, and families who participated in the study, as well as our partners in the BrumiSaTerre research group for fruitful discussions.

Financial support: This work was supported by the French National Research Program for Environmental and Occupational Health of ANSES (EST-2016/1/015).

Authors' addresses: Jean-François Viel and Florence Rouget, Univ Rennes, CHU Rennes, Inserm, EHESP, Irset (Institut de Recherche en Santé, Environnement et Travail) - UMR_S 1085, Rennes, France, E-mails: jeanfrancois.viel@univ-rennes1.fr and florence.rouget@univ-rennes1.fr. Léah Michineau, Univ Rennes, Inserm, EHESP, Irset (Institut de Recherche en Santé, Environnement et Travail) - UMR_S 1085, Pointe-à-Pitre, France, E-mail: leah.michineau@inserm.fr. Céline Garbin, Gwad'Air, Air Quality Monitoring Agency, Petit-Bourg, France, E-mail: c.garbin@gwadair.fr. Christine Monfort and Luc Multigner, Univ Rennes, Inserm, EHESP, Irset (Institut de Recherche en Santé, Environnement et Travail) - UMR_S 1085, Rennes, France, E-mails: christine.monfort@inserm.fr and luc.mutigner@ inserm.fr. Philippe Kadhel, Univ Antilles, CHU Guadeloupe, Univ Rennes, Inserm, EHESP, Irset (Institut de Recherche en Santé, Environnement et Travail) - UMR_S 1085, Pointe-à-Pitre, France, E-mail: philippe.kadhel@ chu-guadeloupe.fr.

\section{REFERENCES}

1. Karanasiou A, Moreno N, Moreno T, Viana M, de Leeuw F, Querol X, 2012. Health effects from Sahara dust episodes in Europe: literature review and research gaps. Environ Int 47: 107-114. 
2. Prospero JM, Blades E, Naidu R, Mathison G, Thani H, Lavoie MC, 2008. Relationship between African dust carried in the Atlantic trade winds and surges in pediatric asthma attendances in the Caribbean. Int J Biometeorol 52: 823-832.

3. Gyan K, Henry W, Lacaille S, Laloo A, Lamsee-Ebanks C, McKay S, Antoine RM, Monteil MA, 2005. African dust clouds are associated with increased paediatric asthma accident and emergency admissions on the Caribbean island of Trinidad. Int J Biometeorol 49: 371-376.

4. Blateau A, Bouobda D, Le Tertre A, Gandar S, Quénel P, 2012. Health effects from desert dust episodes in Martinique, 2001-2006 [in French]. Bull Veille Sanit Antilles Guyane 3: 11-15.

5. Cadelis G, Tourres R, Molinie J, 2014. Short-term effects of the particulate pollutants contained in Saharan dust on the visits of children to the emergency department due to asthmatic conditions in Guadeloupe (French archipelago of the Caribbean). PLoS One 9: e91136.

6. Shah PS, Balkhair T, 2011. Air pollution and birth outcomes: a systematic review. Environ Int 37: 498-516.

7. Dadvand $P$, Basagaña $X$, Figueras $F$, Amoly $E$, Tobias A, de Nazelle A, Querol X, Sunyer J, Nieuwenhuijsen MJ, 2011. Saharan dust episodes and pregnancy. J Environ Monit 13: 3222-3228.

8. Viel JF, Mallet Y, Raghoumandan C, Quénel P, Kadhel P, Rouget F, Multigner L, 2019. Impact of Saharan dust episodes on preterm births in Guadeloupe (French West Indies). Occup Environ Med 76: 336-340.

9. AUDIPOG, 2008. French Population-Based Fetal Growth Charts. Available at: https://www.audipog.net/Courbes-morpho/.Accessed September 20, 2019

10. Slama $\mathrm{R}$ et al., 2008. Meeting report: atmospheric pollution and human reproduction. Environ Health Perspect 116: 791-798. 